\title{
Knowledge and practice of nursing mother`s regarding complementary feeding
}

\author{
Rexona Parvin ${ }^{1,}{ }^{*}$, Pinki Mondal ${ }^{2}$, China Rani Mittra ${ }^{3}$ and Sathi Dastider 4 \\ ${ }^{1}$ District Hospital, Narail, Bangladesh. \\ 2 Bangabandhu Sheikh Mujib Medical College Hospital, Faridpur, Bangladesh. \\ ${ }^{3}$ Khulna Nursing College, Khulna, Bangladesh. \\ ${ }^{4}$ National Institute of Preventive and Social Medicine (NIPSOM), Dhaka, Bangladesh.
}

International Journal of Biological and Pharmaceutical Sciences Archive, 2021, 02(02), 060-071

Publication history: Received on 04 November 2021; revised on 20 December 2021; accepted on 22 December 2021

Article DOI: https://doi.org/10.53771/ijbpsa.2021.2.2.0098

\begin{abstract}
Complementary feeding is the systemic process of introduction of semisolid or solid food in infant at the right time in addition to mother's milk in order to provide needed nutrition to the baby. A cross sectional study was conducted from January to December, 2020 to assess the level of knowledge and practice of nursing mothers regarding complementary feeding. Total 177 nursing mother were selected purposively and interviewed with a pre-tested semi-structured questionnaire. Face to face interview was conducted to collect data. P-value less than 0.05 were set as statistically significant. The knowledge and practice score were categorized into good ( $\geq 70 \%)$, satisfactory (50 to $70 \%)$, and poor $(\leq 50 \%)$. Out of 177 respondents, majority 109(61.6\%) had satisfactory knowledge regarding complementary feeding, $33(18.6 \%)$ had good knowledge and rest of them 35(19.8\%) had poor knowledge regarding complementary feeding among the nursing mother. On the other hand $62.7 \%$ respondents had poor Practices, $24.9 \%$ had satisfactory practices and $12.4 \%$ had good practices regarding complementary feeding among the nursing mothers. There was highly significant association between knowledge and practice of complementary feeding ( $p<.000)$. Nursing mother's knowledge regarding complementary feeding time was inadequate and practices were inappropriate. . It is the responsibility of health professionals to pass on the current information about proper infant feeding to mothers/care takers for promoting the healthy complementary feeding of the breastfeed child.
\end{abstract}

Keywords: Complementary feeding; Nursing mother; Exclusive breast feeding; Hygienic principles; Food groups

\section{Introduction}

Nutrition is a vital component of health promotion and disease prevention. The major effects of under nutrition are believed to occur during the first 2 years of human life. This is because, at this stage, under nutrition causes irreversible damage to physical, mental, and social development of the child transcending into reduced intellectual potential at adulthood [1]. The first two years of life provide a critical window of opportunity for ensuring children's appropriate growth and development through optimal feeding.

Complementary feeding should be started when breast milk is no longer enough to meet the nutritional needs of the infant [2].The transition from exclusive breast feeding to semisolid food is a very vulnerable period because it is the time when malnutrition starts in many infants, contributing significantly to the high prevalence of malnutrition and infection in children less than five years of age worldwide [3].

According to the WHO guidelines complementary feeding should be started at 6 months of age along with breast feeding up to 2 years or more (WHO, 2016 and WHO/UNICEF, 1998).

\footnotetext{
* Corresponding author: Rexona Parvin

District Hospital, Narail, Bangladesh. Email: ashees2020@gmail.com

Copyright (C) 2021 Author(s) retain the copyright of this article. This article is published under the terms of the Creative Commons Attribution Liscense 4.0.
} 
Complementary feeding foods should be adequate in nutrition, appropriate in consistency, given in sufficient quantity and hygienic. According to the WHO guidelines complementary feeding should be started at 6 months of age along with breast feeding up to 2 years or more [4] [5].

Improper complementary feeding or complementary feeding practices, coupled with high rates of infectious diseases, are the principal proximate causes of malnutrition during the first two years of life [6]. For this reason, it is essential to ensure that mothers and caregivers are provided with appropriate guidance regarding optimal feeding of infants and young children.

Understanding the decision making process, social beliefs, knowledge, attitude and practices of complementary feeding is an important step prior to designing an intervention strategy to prevent malnutrition in children. Aim to assess the level of knowledge and practices of nursing mothers regarding complementary feeding.

\section{Material and methods}

\subsection{Study design}

The study design was a descriptive type of cross-sectional study.

\subsection{Study population $\&$ Sample}

Study population were mothers of children aged 6-23 months age, sample population was selected purposively from the selected upazillas.

\subsection{Study place}

The study was conducted in E.P.I. center and pediatric outdoors of Upazilla Health Complex, Abhoynagor and Bagharpara, Jashore.

\subsection{Study period}

The study was conducted for the one year during the period of 1st January to 31st December 2020.

\subsection{Sample size}

The sampling size was determined by the following formula. Sample size for that proposed study was calculated by the following formula-

$$
\mathrm{z}^{2} \mathrm{pq} / \mathrm{d}^{2}
$$

Here,

$\mathrm{n}=$ assumed sample size

$\mathrm{z}=$ the standard normal deviation usually set at 1.96 at $95 \%$ confidence level

$\mathrm{p}=$ the proportion in the population possessing the characteristics of interest.

$q=1-p$, here, $1-0.74=0.26$

$\mathrm{d}=$ Acceptable margin of error or precision $(5 \%)=0.05$

From the previous study, proportion of complementary feeding practices among mothers is $74 \%$; value of $p=0.74$, (Saleh, F., et al., 2014)

From the above formula the estimated sample size is 295 .

*Though the actual sample size was 295 but data was collected from 177 respondents due to COVID - 19 pandemic situations. 


\subsection{Inclusion Criteria}

- Mothers who willing to participate.

- $\quad$ Mothers of children aged 6-23 months.

\subsection{Exclusion Criteria}

- $\quad$ Physically ill mothers and children.

- Mentally ill mothers and children.

\subsection{Sampling Technique}

Purposive sampling technique was used. Out of the study population the individual sample units were selected according to selection criteria.

\subsection{Data Collection tools}

A pre-tested modified Semi-structured self-administered questionnaire was developed by using selected variables according to objectives. The questionnaire was divided into 3 sections including 1) Demographic Questionnaire, 2) Knowledge regarding complementary feeding Questionnaire, 3) Practice regardingcomplementary feeding Questionnaire.

\subsection{Data collection technique}

Face to face interview.

\subsection{Data management and analysis plan}

After completion of data collection, all data were processed through computer program (SPSS version-25). Data were analysed using descriptive and inferential statistics. Descriptive statistics were used for presenting demographic characteristics. Practice levels were described in terms of frequency, percentage, mean, standard deviation, and range. Chi-squire test was used to examine the significance among the level of nursing mother knowledge and practice.

\section{Results}

This cross sectional study was carried out among 177 nursing mother to assess the level of knowledge and practices of nursing mothers regarding complementary feeding in E.P.I. center and pediatric outdoors of Upazilla Health Complex, Abhaynagar and Bagharpara, Jashore. This chapter represents findings of those data.

Table 1 Socio-demographic status of the respondents

\begin{tabular}{|c|c|c|}
\hline $\begin{array}{c}\text { Age group } \\
\text { (in complete years) }\end{array}$ & $\begin{array}{c}\text { Frequency } \\
\text { (n) }\end{array}$ & $\begin{array}{c}\text { Percent } \\
(\%)\end{array}$ \\
\hline Below 20 years & 45 & $25.4 \%$ \\
\hline $20-30$ years & 107 & $60.5 \%$ \\
\hline $31-40$ years & 24 & $13.6 \%$ \\
\hline Above 40 years & 1 & $.6 \%$ \\
\hline \multicolumn{3}{|c|}{ Mean ( \pm SD) $25.20( \pm 5.292)$} \\
\hline \multicolumn{3}{|l|}{ Level of education } \\
\hline No formal education & 8 & $4.5 \%$ \\
\hline Primary education & 33 & $18.6 \%$ \\
\hline Up to JSC & 56 & $31.6 \%$ \\
\hline Up to SSC & 35 & $19.8 \%$ \\
\hline HSC & 24 & $13.6 \%$ \\
\hline Graduate & 12 & $6.8 \%$ \\
\hline Post graduate & 9 & $5.1 \%$ \\
\hline \multicolumn{3}{|l|}{ Occupation } \\
\hline
\end{tabular}




\begin{tabular}{|c|c|c|}
\hline Housewife & 171 & $96.6 \%$ \\
\hline Service holder & 6 & $3.4 \%$ \\
\hline \multicolumn{3}{|c|}{ Monthly family income } \\
\hline Up to $10000 /-$ & 5 & $2.8 \%$ \\
\hline $11000-20000 /-$ & 102 & $57.6 \%$ \\
\hline $21000-30000 /-$ & 52 & $29.4 \%$ \\
\hline Above $30000 /-$ & 18 & $10.2 \%$ \\
\hline \multicolumn{3}{|l|}{ Gender of child } \\
\hline Male & 94 & 53.1 \\
\hline Female & 83 & 46.9 \\
\hline \multicolumn{3}{|c|}{ Number of children } \\
\hline One & 73 & $41.2 \%$ \\
\hline Two & 80 & $45.2 \%$ \\
\hline Three & 16 & $9.0 \%$ \\
\hline Above three & 8 & $4.5 \%$ \\
\hline \multicolumn{3}{|c|}{ Spouse educational status } \\
\hline Primary education & 24 & $13.5 \%$ \\
\hline Up to JSC & 55 & $34.4 \%$ \\
\hline Under graduate & 61 & $40 \%$ \\
\hline Post graduate & 37 & $20.9 \%$ \\
\hline \multicolumn{3}{|l|}{ Spouse Occupation } \\
\hline Farmer & 8 & $4.5 \%$ \\
\hline Labor & 77 & $43.5 \%$ \\
\hline Service & 31 & $17.5 \%$ \\
\hline Business & 61 & $34.5 \%$ \\
\hline \multicolumn{3}{|c|}{ Person to take care of child } \\
\hline Myself & 172 & $97.2 \%$ \\
\hline Husband & 5 & $2.8 \%$ \\
\hline \multicolumn{3}{|c|}{ Person to take care of living expenses } \\
\hline Myself & 6 & $3.4 \%$ \\
\hline Husband & 171 & $96.6 \%$ \\
\hline Total & 177 & $100.0 \%$ \\
\hline
\end{tabular}

Table 1 shows the socio-demographic status of the respondents. Out of 177 respondents, more than half 107 (60.5\%) were the age group within 20 -30 years, 24(13.6\%) were age group $31-40$ years, 45(25.4\%) were age group below 20 years and only $1(.6 \%)$ were above 40 years. The mean age of the respondents was $25.20( \pm 5.292)$ years. From them 56 (31.6\%) education level were up to JSC, 33(18.6\%) were up to primary education, 24 (13.6\%) were up to HSC, 12(6.8\%) were up to graduate and only $9(5.1 \%)$ respondents education level were up to post graduation and $171(96.6 \%)$ were housewife and rest of them 6(3.4\%) were service holder. More than half 102(57.6\%) respondents monthly family income were up to 11000 - 20000/-, here, 52(29.4\%) monthly family income were up to 21000 - 30000/-, from them $5(2.8 \%)$ monthly family income were up to $10000 /$ - and only $18(10.2 \%)$ respondents monthly family income were up to above 30000/-. Here, majority 94 (53.1\%) of the respondent's gender of child were male and rest of them 83(46.9\%) gender of child were female and less than half $80(45.2 \%)$ of the respondents had two children, $73(41.2 \%)$ of the respondents had one child, $16(9.0 \%)$ of the respondents had three children and rest of them $8(4.5 \%)$ of the respondents had more than 3 children. Out of 177 respondents, 55(34\%) respondent's spouse education were up to JSC, 24(13.5\%) respondent's spouse education were up to primary level, 61(40\%) respondent's spouse education were up to under graduate and rest of them $37(20.9 \%)$ respondent's spouse education were up to post graduation. Most of the respondents $77(43.5 \%)$ spouse occupation was labor, $61(34.5 \%)$ spouse occupation was business, 31(17.5\%) spouse 
occupation was service and only $8(4.5 \%)$ spouse occupation was farmer. Among the 177 respondents, majority of the respondents $172(97.2 \%)$ to take care of their child by herself and only $5(2.8 \%)$ of the respondents to take care of child by their husband and $171(96.6 \%)$ of the respondent's to take care their living expenses by husband, $6(3.4 \%)$ of the respondent`s to take care their living expenses by herself.

Table 2 Knowledge about complementary feeding of the respondents ( $\mathrm{n}=177)$

\begin{tabular}{|c|c|c|}
\hline complementary feeding & Frequency (n) & Percent (\%) \\
\hline $\begin{array}{l}\text { Extra food with breast milk after six months age is } \\
\text { complementary feeding }\end{array}$ & 167 & $94.4 \%$ \\
\hline No idea & 10 & $5.6 \%$ \\
\hline \multicolumn{3}{|l|}{ Starting time of complementary feeding } \\
\hline Before completion of 6 months & 25 & $14.1 \%$ \\
\hline After 6 months & 143 & $80.8 \%$ \\
\hline From 6 months & 1 & $.6 \%$ \\
\hline No idea & 8 & $4.5 \%$ \\
\hline \multicolumn{3}{|l|}{ Knowledge \& benefit of Complementary feeding at right time } \\
\hline Growth and development of child & 165 & $93.2 \%$ \\
\hline Only development & 3 & $1.7 \%$ \\
\hline No idea & 9 & $5.1 \%$ \\
\hline \multicolumn{3}{|l|}{ Appropriate source of complementary feeding } \\
\hline Baby food from market & 14 & $7.9 \%$ \\
\hline Homemade food & 163 & $92.1 \%$ \\
\hline \multicolumn{3}{|l|}{ Late complementary feeding may leading } \\
\hline Well nutrition of child & 18 & $10.2 \%$ \\
\hline Malnutrition of child & 143 & $80.8 \%$ \\
\hline No idea & 16 & $9.0 \%$ \\
\hline \multicolumn{3}{|l|}{ Feeding practice followed for female child } \\
\hline $\begin{array}{l}\text { Provide same time, food, frequency and amount like as male } \\
\text { child }\end{array}$ & 174 & $98.3 \%$ \\
\hline $\begin{array}{l}\text { Late start of complementary feeding with provide less } \\
\text { amount of food rather than male child }\end{array}$ & 3 & $1.8 \%$ \\
\hline \multicolumn{3}{|l|}{ Way to ensure the foods safety and hygiene } \\
\hline Nothing to do & 41 & $23.2 \%$ \\
\hline Wash hands and clean necessary utensils. & 128 & $72.3 \%$ \\
\hline No idea & 8 & $4.5 \%$ \\
\hline Total & 177 & $100.0 \%$ \\
\hline
\end{tabular}

Table 2 shows to knowledge about complementary feeding of the respondents. Among the 177 respondents, $167(94.4 \%)$ knew that extra food with breast milk after six months age is complementary feeding and rest of them $10(5.6 \%)$ had no idea about complementary feeding. Majority $143(80.8 \%)$ of the respondents think before 6 months complementary feed should be introduced in addition to breastfeeding, 25(14.1\%) think after 6 months complementary 
feed should be introduced in addition to breastfeeding, 8(4.5\%) had no idea and only $1(.6 \%)$ respondent think complementary feed should be introduced in addition to breastfeeding. Most of the respondents 165(93.2\%) think complementary feeding with breastfeeding in appropriate time ensures growth and development of child, 3(1.7\%) think only development and $9(5.1 \%)$ respondents have no idea. Majority $163(92.1 \%)$ give opinion homemade food is appropriate source of complementary feeding and 14(7.9\%) give opinion baby food from market is appropriate source of complementary feeding. Here, $143(80.8 \%)$ give opinion, late complementary feeding may lead to malnutrition of child, 18(10.2\%) give opinion, late complementary feeding may lead to well nutrition of child and 16(9.0\%) respondent had no idea about effect of late complementary feeding. Out of 177 respondents, majority $174(98.3 \%)$ give opinion, they provide same time, food, frequency and amount to female child same as male child, and $3(1.8 \%)$ respondents give opinion, they late start of complementary feeding with provide less amount of food to female child rather than male child and $128(72.3 \%)$ wash hands and clean necessary utensils to ensure the foods safety and hygiene, $41(23.2 \%)$ nothing to do to ensure the foods safety and hygiene, and $8(4.5 \%)$ had no idea about way to ensure the foods safety and hygiene.

Table 3 Knowledge about breastfeeding of the respondents $(n=177)$

\begin{tabular}{|l|c|c|}
\hline \multicolumn{1}{|c|}{ Period of exclusive breastfeeding } & Frequency (n) & Percent (\%) \\
\hline First 6 months & 153 & $86.4 \%$ \\
\hline First 4 months & 9 & $5.1 \%$ \\
\hline First 5 months & 6 & $3.4 \%$ \\
\hline No idea & 9 & $5.1 \%$ \\
\hline Appropriate times a mother should breast feed a child after 6 months \\
\hline On demand & 172 & $97.2 \%$ \\
\hline No idea & 5 & $2.9 \%$ \\
\hline Appropriate times of a mother should stopped breastfeed of a child \\
\hline 0 - 2 yrs. & 161 & $91.0 \%$ \\
\hline No idea & 16 & $9.1 \%$ \\
\hline Total & 177 & $100.0 \%$ \\
\hline
\end{tabular}

Table 3 shows to knowledge about breastfeeding of the respondents. From the 177 respondents, 153(86.4\%) give opinion first 6 months baby feed only breast milk without complementary feed, $9(5.1 \%)$ give opinion first 5 months baby feed only breast milk without complementary feed, 6(3.4\%) give opinion first 6 months baby feed only breast milk without complementary feed and $9(5.1 \%)$ give opinion they have no idea about months baby feed only breast milk without complementary feed. From them, 172(97.2\%) think appropriate times a mother breast feed a child after 6 months depends on demand and 5(2.9\%) had no idea about appropriate times a mother breast feed a child after 6 months. Most 161(91.0\%) of the respondents give opinion 0 - 2 years a mother breastfeed a child before stopping and $16(9.1 \%)$ had no idea about appropriate times should a mother breastfeed a child before stopping.

Table 4 Knowledge about meal frequency of complementary feed of the respondents $(n=177)$

\begin{tabular}{|l|c|c|}
\hline $\begin{array}{c}\text { Minimum meal frequency of complementary feed } \\
\text { giving in a day at the age of 6- 8 months }\end{array}$ & Frequency (n) & Percentage (\%) \\
\hline Two - three times & 114 & $64.4 \%$ \\
\hline At least five times & 19 & $10.7 \%$ \\
\hline At least six times & 2 & $1.1 \%$ \\
\hline No idea & 42 & $23.7 \%$ \\
\hline Minimum meal frequency of complementary feed giving in a day at the age of 9- 11 months \\
\hline At least two times & 10 & $5.6 \%$ \\
\hline Three -four times & 26 & $14.7 \%$ \\
\hline At least 4 times & 114 & $64.4 \%$ \\
\hline No idea & 27 & $15.3 \%$ \\
\hline
\end{tabular}




\begin{tabular}{|l|c|c|}
\hline \multicolumn{3}{|c|}{ Minimum meal frequency of complementary feed giving in a day at the age of 12-24 months } \\
\hline Three times daily & 72 & $40.7 \%$ \\
\hline Three -four times & 47 & $26.6 \%$ \\
\hline Five times daily & 31 & $17.5 \%$ \\
\hline No idea & 27 & $15.3 \%$ \\
\hline \multicolumn{2}{|l|}{ Times to offer additional nutritious snacks at the age of $\mathbf{1 2}-\mathbf{2 4}$ months } \\
\hline 1-2 times per day. & 130 & $73.4 \%$ \\
\hline 3-4 times per day. & 24 & $14.2 \%$ \\
\hline No idea & 22 & $12.4 \%$ \\
\hline Total & 177 & $100.0 \%$ \\
\hline
\end{tabular}

Table 4 shows to knowledge about minimum meal frequency of complementary feed of the respondents. Among the 177 respondents, more than half $114(64.4 \%)$ of the respondents two - three times giving complementary feed in a day at the age of 6- 8 months, 19(10.7\%) at least five times giving complementary feed in a day at the age of 6- 8 months, $2(1.1 \%)$ at least six times giving complementary feed in a day at the age of $6-8$ months and $42(23.7 \%)$ respondents had no idea about Minimum frequency of complementary feed giving in a day at the age of 6- 8 months. More than half $114(64.4 \%)$ of the respondents at least 6 times giving complementary feed in a day at the age of 9- 11 months, $26(14.7 \%)$ three -four times giving complementary feed in a day at the age of 9-11 months, 10 (5.6\%) at least two times giving complementary feed in a day at the age of $9-11$ months and 27(15.3\%) respondents had no idea about Minimum frequency of complementary feed giving in a day at the age of 9- 11 months. Here, less than half $72(40.7 \%)$ of the respondents three times daily giving complementary feed in a day at the age of 12 - 24 months, $47(26.6 \%)$ three -four times giving complementary feed in a day at the age of $12-24$ months, $31(17.5 \%)$ five times daily giving complementary feed in a day at the age of 12- 24 months and 27(15.3\%) respondents had no idea about Minimum frequency of complementary feed giving in a day at the age of $12-24$ months.

Out of 177 respondents, $130(73.4 \%)$ per day 1-2 times offer additional nutritious snacks at the age of $12-24$ months, 25(14.2\%)per day 3-4 times offer additional nutritious snacks at the age of $12-24$ months, and 22(12.4\%) of the respondents had no idea about times to offer additional nutritious snacks at the age of $12-24$ month.

Table 5 Practice about complementary feeding of the respondents $(n=177)$

\begin{tabular}{|l|c|c|}
\hline \multicolumn{1}{|c|}{$\begin{array}{c}\text { Introduce complementary feeds at } 6 \text { months of age } \\
\text { while continuing to breastfeed }\end{array}$} & Frequency (n) & Percent (\%) \\
\hline Yes & 130 & $73.5 \%$ \\
\hline Sometimes & 00 & $00 \%$ \\
\hline No & 47 & $26.6 \%$ \\
\hline Continue frequent, on-demand breastfeeding until two years of age \\
\hline Yes & 148 & $83.6 \%$ \\
\hline Sometimes & 12 & $6.8 \%$ \\
\hline No & 17 & $9.6 \%$ \\
\hline $\begin{array}{l}\text { Start with small amounts of food and increase the quantity as the child gets older from 6 } \\
\text { month }\end{array}$ & 93 & $52.5 \%$ \\
\hline Yes & 76 & $42.9 \%$ \\
\hline Sometimes & 8 & $4.6 \%$ \\
\hline No & 78 & $44.1 \%$ \\
\hline Gradually increase food consistency and variety as the infant gets older \\
\hline Yes & 82 & $46.3 \%$ \\
\hline Sometimes & 17 & $9.6 \%$ \\
\hline No & \\
\hline Provide 1-2 times additional nutritious snacks per day \\
\hline
\end{tabular}




\begin{tabular}{|l|c|c|}
\hline Yes & 58 & $32.8 \%$ \\
\hline Sometimes & 76 & $42.9 \%$ \\
\hline No & 43 & $24.3 \%$ \\
\hline Feed a variety of foods that ensure nutrient needs are met & \multicolumn{2}{|l|}{} \\
\hline Yes & 80 & $45.2 \%$ \\
\hline Sometimes & 71 & $40.1 \%$ \\
\hline No & 26 & $14.7 \%$ \\
\hline Total & 177 & $100.0 \%$ \\
\hline
\end{tabular}

Table 5 shows Practice about complementary feeding of the respondents. Out of 177 respondents, majority 130 (73.5\%) introduce complementary feeds at 6 months of age while continuing to breastfeed while 47(26.6\%) respondents did not introduce complementary feeds at 6 months of age while continuing to breastfeed. Majority 148(83.6\%) continuing on-demand breastfeeding until two years of age, 12(6.8\%) sometimes continue on-demand breastfeeding until two years of age and $17(9.6 \%)$ respondents did not continuing on-demand breastfeeding until two years of age. Out of 177 respondents, 93(52.5\%) start at 6 months of age with small amounts of food and increase the quantity as the child gets older, 76(42.9\%) sometimes start at 6 months of age with small amounts of food and increase the quantity as the child gets older and $8(4.6 \%)$ did not start at 6 months of age with small amounts of food and increase the quantity as the child gets older. Here, respondents, 78(44.1\%) gradually increase food consistency and variety as the infant gets older, $82(46.3 \%)$ sometimes gradually increase food consistency and variety as the infant gets older and $17(9.6 \%)$ did not gradually increase food consistency and variety as the infant gets older and 58(32.8\%)provide 1-2 times additional nutritious snacks (such as a piece of fruit or bread or chapatti with nut paste) per day, 76(42.9\%) sometimes provide 1-2 times additional nutritious snacks (such as a piece of fruit or bread or chapatti with nut paste) per day and 43(24.3\%) did not provide 1-2 times additional nutritious snacks (such as a piece of fruit or bread or chapatti with nut paste) per day. From the total respondents, $80(45.2 \%)$ feed a variety of foods to ensure that nutrient needs are met, $71(40.1 \%)$ sometimes feed a variety of foods to ensure that nutrient needs are met and $26(14.7 \%)$ did not feed a variety of foods to ensure that nutrient needs are met.

Table 6 Distribution of the respondents according to give vitamin A- and mineral rich complementary feed daily $(\mathrm{n}=177)$

\begin{tabular}{|l|c|c|}
\hline Give vitamin A-rich fruits, vegetables and pulses daily & Frequency (n) & Percent (\%) \\
\hline Yes & 46 & $26.0 \%$ \\
\hline Sometimes & 96 & $54.2 \%$ \\
\hline No & 35 & $19.8 \%$ \\
\hline Use fortified complementary foods or vitamin-mineral supplements for the infant \\
\hline Yes & 43 & $24.3 \%$ \\
\hline Sometimes & 57 & $32.2 \%$ \\
\hline No & 77 & $43.5 \%$ \\
\hline
\end{tabular}

Increase fluid intake during illness, including more frequent breastfeeding, and encourage the child to eat soft, varied, appetizing, favorite foods

\begin{tabular}{|l|c|c|}
\hline Yes & 46 & $26.0 \%$ \\
\hline Sometimes & 94 & $53.1 \%$ \\
\hline No & 37 & $20.9 \%$ \\
\hline
\end{tabular}

After illness, give more food often than usual and encourage the child to eat more

\begin{tabular}{|l|c|c|}
\hline Yes & 37 & $20.9 \%$ \\
\hline Sometimes & 109 & $61.6 \%$ \\
\hline No & 31 & $17.5 \%$ \\
\hline Give meat/poultry/ fish or eggs should be eaten daily & \multicolumn{2}{|c|}{} \\
\hline Yes & 120 & $67.8 \%$ \\
\hline Sometimes & 49 & $27.7 \%$ \\
\hline
\end{tabular}




\begin{tabular}{|l|c|c|}
\hline No & 8 & $4.5 \%$ \\
\hline Family members who have food taboos about specific items \\
\hline Yes & 58 & $32.8 \%$ \\
\hline No & 119 & $67.2 \%$ \\
\hline Total & 177 & $100.0 \%$ \\
\hline
\end{tabular}

Table 6 shows, Distribution of the respondents according to give vitamin A- and mineral rich complementary feed daily. Out of 177 respondents 46(26.0\%) give vitamin A-rich fruits, vegetables and pulses daily, 96(54.2\%) sometimes give vitamin A-rich fruits, vegetables and pulses daily and 35(19.8\%) did not give vitamin A-rich fruits, vegetables and pulses daily and $43(24.3 \%)$ use fortified complementary foods or vitamin-mineral supplements for the infant, as needed, $57(32.2 \%)$ did not use fortified complementary foods or vitamin-mineral supplements for the infant, as needed. Here, 46(26.0\%) increase fluid intake during illness, 94(53.1\%) sometimes increase fluid intake during illness, i and $37(20.9 \%)$ did not increase fluid intake during illness, including more frequent breastfeeding, and encourage the child to eat soft, varied, appetizing, favorite foods. Out of 177 respondents, 37(20.9\%) after illness, give food more often than usual and encourage the child to eat more, 109(61.6\%) sometimes after illness, give food more often than usual and encourage the child to eat more and 31(17.5\%) did not after illness, give food more often than usual and encourage the child to eat more. Majority of the respondent, 120(67.8\%)give meat, poultry, fish or eggs should be eaten daily, or as often as possible, $49(27.7 \%)$ sometime give meat, poultry, fish or eggs should be eaten daily, or as often as possible and $8(4.5 \%)$ did not give meat, poultry, fish or eggs should be eaten daily, or as often as possible and $58(32.8 \%)$ family members who have food taboos about specific items and $119(67.2 \%)$ respondents family members who have not food taboos about specific items.

Table 7 Distribution of the respondents according to association between Knowledge and Practices of Complementary feeding $(n=177)$

\begin{tabular}{|c|c|c|c|c|c|c|}
\hline & & \multicolumn{3}{|c|}{ Practice Level } & \multirow[t]{2}{*}{ Total } & \multirow[t]{2}{*}{ Significance } \\
\hline & & Poor & Satisfactory & Good & & \\
\hline \multirow{3}{*}{ 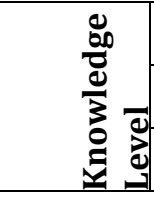 } & Poor & 32 & 2 & 1 & 35 & \multirow[t]{3}{*}{$\chi 2=17.290^{\mathrm{a}}$} \\
\hline & Satisfactory & 64 & 30 & 15 & 109 & \\
\hline & Good & 15 & 12 & 6 & 33 & \\
\hline \multicolumn{2}{|l|}{ Total } & 111 & 44 & 22 & 177 & $\mathrm{p}$ value $=.000$ \\
\hline
\end{tabular}

Table 7 represent that Chi-Square test was performed, there was a highly significance association between Knowledge and Practices of Complementary feeding $(\mathrm{p}<.000)$.

Figure 1 shows the distribution of the respondents according to knowledge regarding complementary feeding. Out of 177 respondents, majority $109(61.6 \%)$ had satisfactory knowledge regarding complementary feeding, 33(18.6\%) had good knowledge and rest of them $35(19.8 \%)$ had poor knowledge regarding complementary feeding among the nursing mother.

Figure 2 shows the distribution of the respondents according Practices regarding complementary feeding. Out of 177 respondents, majority 111(62.7\%) respondents had Poor Practices regarding complementary feeding, 44(24.9\%) had Satisfactory Practices and 22(12.4\%) had good Practices regarding complementary feeding among the nursing mothers. 


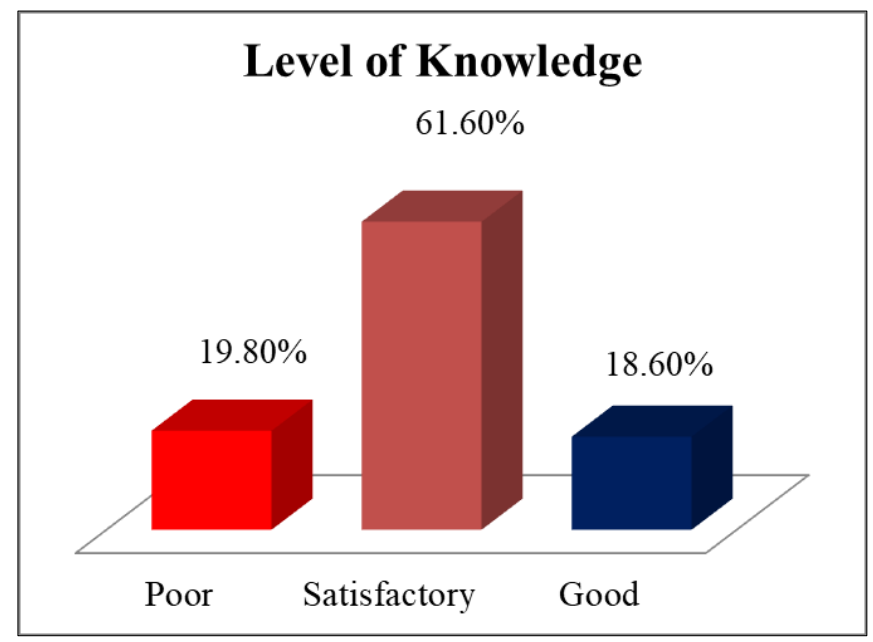

Figure 1 Distribution of the respondents according to knowledge regarding complementary feeding $(n=177)$

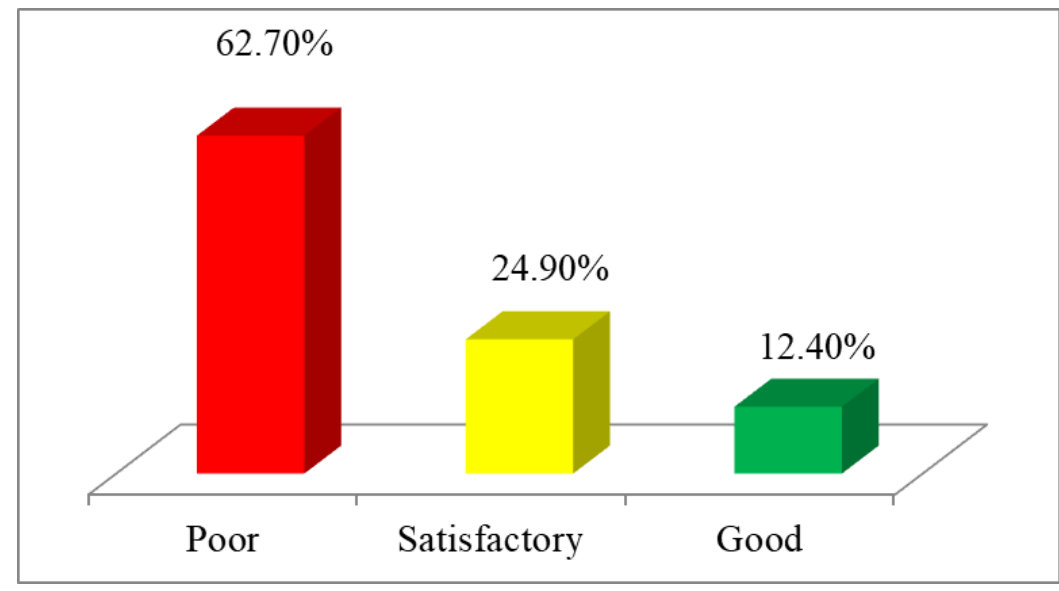

Figure 2 Distribution of the respondents according to Practices regarding complementary feeding $(n=177)$

\section{Discussion}

Optimal nutrition during first two years of life is crucial for the survival, healthy growth, and development of infants and young children.

In present study, out of 177 respondents, majority 130 (73.5\%) introduce complementary feeds at 6 months of age while continuing to breastfeed while 47(26.6\%) respondents did not introduce complementary feeds at 6 months of age while continuing to breastfeed and Out of 177 respondents, 148(83.6\%) continuing on-demand breastfeeding until two years of age, $12(6.8 \%)$ sometimes continue on-demand breastfeeding until two years of age and $17(9.6 \%)$ respondents did not continuing on-demand breastfeeding until two years of age. There was a gap between knowledge of complementary feeding and its practice.

WHO recommended introducing complementary foods at 6 months of age (180 days) while continuing to breastfeed. Initiation of complementary food among infants aged 6-9 months was 76\% [7]. According to the Bangladesh Demographic Health Survey 2006- 2007, the rate of introduction of complementary food at 6-8 months of age was 84\% in Sri Lanka. This rate was 70\% in Nepal 69 and 76\% in Bangladesh. In India only half (55\%) of the children aged between 6 and 8 months were introduced to solid foods but this rate was 39\% in Pakistan [8].

Here, among the 177 respondents, 167(94.4\%) knew that extra food with breast milk after six months age is complementary feeding and rest of them $10(5.6 \%)$ had no idea about complementary feeding. More than half $114(64.4 \%)$ of the respondents two - three times giving complementary feed in a day at the age of 6 - 8 months, and $42(23.7 \%)$ respondents had no idea about Minimum frequency of complementary feed giving in a day at the age of $6-8$ month. More than half $114(64.4 \%)$ of the respondents at least 4 times giving complementary feed in a day at the age of 
9- 11 months, 26(14.7\%) three -four times giving complementary feed in a day at the age of 9- 11 months, and $27(15.3 \%)$ respondents had no idea about Minimum frequency of complementary feed giving in a day at the age of 911 months. Less than half $72(40.7 \%)$ of the respondents three times daily giving complementary feed in a day, $47(26.6 \%)$ three -four times giving complementary feed in a day at the age of $12-24$ months, 31(17.5\%) and $27(15.3 \%)$ respondents had no idea about Minimum frequency of complementary feed giving in a day at the age of $12-24$ months.

Knowledge of complementary feeding was low (14.9\%) and was associated with older mothers' age, being married, and higher level of education. The prevalence of timely initiation of complementary feeding (47.9\%), dietary diversity $(16.0 \%)$ and minimum acceptable diet for children between 6 and 9 months (16\%) were low. Overall, appropriate complementary feeding practice was low (47.0\%) and associated with higher level of mothers' education and occupation [9].

Out of 177 respondents, majority 109(61.6\%) had satisfactory knowledge regarding complementary feeding, $33(18.6 \%)$ had good knowledge and rest of them $35(19.8 \%)$ had poor knowledge regarding complementary feeding among the nursing mother and majority 111(62.7\%) respondents had Poor Practices regarding complementary feeding, 44(24.9\%) had Satisfactory Practices and 22(12.4\%) had good Practices regarding complementary feeding among the nursing mothers and there was a highly significance association between Knowledge and Practice of Complementary feeding $(\mathrm{p}<.000)$. There was a highly significance association between Knowledge and Practices of Complementary feeding $(\mathrm{p}<.000)$.

In present study explore that, the mother had some misconception about complementary feedings. The mothers said that the child does not get enough breast milk so they started complementary feeding, though they know the ideal time to start complementary feeding is from 6 months of age. Some mother told that the child stomach was fulfill by breast milk and it is enough to meet baby`s demand so, they didn't start complementary feeding at six months of age.. Some mothers' think that oranges, apples, pomegranate have more nutrients value, but unluckily they could not able to buy it due to financial crisis. They said that if the food is affordable then they could buy nutritious foods easily. Many mothers mentioned that their children do not want to eat. Most of mothers said that they bought Quail eggs and it contains more protein as needed.

\section{Conclusion}

There is lack of knowledge in mothers regarding complementary feeding, false beliefs and attitudes, illiteracy, low socioeconomic status of rural mothers, thus leading to malnutrition of the child. Hence, mothers should be educated properly regarding complementary feeding, foods, preparation and practice to prevent malnutrition and improve the health status of the children.

\section{Compliance with ethical standards}

\section{Acknowledgments}

I am deeply indebted to my supervisor Dr. Sathi Dastider, Assistant Professor, Department of Population Dynamics, NIPSOM and express my best regards, hearty gratitude and sincere appreciation to his for his guidance, inspiration and close co-operation throughout the period of this study.

\section{Disclosure of conflict of interest}

None to declare.

\section{Statement of informed consent}

Informed consent was obtained from all individual participants included in the study.

\section{References}

[1] Nassanga P, Okello-Uma I, Ongeng D. The status of nutritional knowledge, attitude and practices associated with complementary feeding in a post-conflict development phase setting: The case of Acholi sub-region of Uganda. Food science \& nutrition. 2018; 6(8): 2374-2385.

[2] Elizebeth KE. Nutrition and child development. 3rd edition, Paras Medical Publisher, India. 2007; 23-28. 
[3] Ruth A, Lawrence R, Lawrence M. Breast feeding a guide for the medical profession. 6th edition, Elsevier Publications. US. 2005; 357-375.

[4] WHO. Global strategy for infant and young child feeding. Geneva: World Health Organization. 2016.

[5] WHO/UNICEF. Complementary feeding of young children in developing countries: a review of current scientific knowledge. Geneva: World Health Organization, WHO/NUT/98.1:1998.

[6] WHO. Global Strategy for Infant and Young Child Feeding. Geneva: World Health Organization. WHA55/2002/REC/1 Annex 2. 2002.

[7] Kabir AI, Roy SK, Khatoon S. Development of a complementary feeding manual for Bangladesh. Final Research Results. 2009.

[8] Mihrshahi S, Kabir I, Roy SK, Agho KE, Senarath U, Dibley MJ. Determinants of infant and young child feeding practices in Bangladesh: Secondary data analysis of Demographic and Health Survey 2004. Food Nutr Bull. Jun 2010; 31(2): 295-313.

[9] Olatona FA, Adenihun JO, Aderibigbe SA, et al. Complementary feeding knowledge, practices, and dietary diversity among mothers of under-five children in an urban community. International Journal of MCH and AIDS. 2017; 6: 46-59. 